\title{
Habitat partitioning of denitrifying bacterial communities carrying nirS or nirK genes in the stratified water column of Lake Kinneret, Israel
}

\author{
Pilar Junier $^{1,2, *}$, Ok-Sun Kim ${ }^{2}$, Karl-Paul Witzel ${ }^{2}$, Johannes F. Imhoff ${ }^{3}$, Ora Hadas ${ }^{4}$ \\ ${ }^{1}$ École Polytechnique Fédérale de Lausanne, 1015 Lausanne, Switzerland \\ ${ }^{2}$ Max Planck Institute for Evolutionary Biology, 24306 Plön, Germany \\ ${ }^{3}$ Leibniz Institute of Marine Sciences, University of Kiel, 24105 Kiel, Germany \\ ${ }^{4}$ Israel Oceanographic and Limnological Research, Kinneret Limnological Laboratory, 14950 Migdal, Israel
}

\begin{abstract}
The community composition of denitrifying bacteria was studied in the stratified water column of Lake Kinneret. The nitrite reductase genes nirS and nirK were amplified by PCR from water samples taken at 1, 14, 19 and $22 \mathrm{~m}$ depth, which represent the epi-, meta- and hypolimnion of the lake. The PCR products were analyzed with terminal restriction fragment length polymorphism (T-RFLP) and clone libraries. The highest diversity of nirS denitrifying communities was observed at $1 \mathrm{~m}$ depth. According to the T-RFLP profiles and clone libraries of nirS products, 2 groups of denitrifiers were common to and dominant in all depths. Deduced protein sequences from one of these groups displayed low identity $(77 \%)$ with other nirS sequences reported in GenBank. Denitrifying bacterial communities with nirK were most diverse at $22 \mathrm{~m}$ and showed highest similarity to those at $19 \mathrm{~m}$ depth. Sequences unrelated to nirK dominated the clone libraries from $1 \mathrm{~m} \mathrm{depth}$, suggesting that denitrifying bacteria with copper-containing nitrite reductase were less frequent at this depth. The results suggest that microorganisms with nirK and those with nirS respond differently to the environmental conditions in the stratified water column of Lake Kinneret.
\end{abstract}

KEY WORDS: nirS $\cdot$ nirK $\cdot$ T-RFLP $\cdot$ Lake Kinneret

Resale or republication not permitted without written consent of the publisher

\section{INTRODUCTION}

Biological denitrification is a respiratory process involving electron transport phosphorylation and defined as the enzymatic reduction of nitrogen oxides with the production of nitric oxide (NO), nitrous oxide $\left(\mathrm{N}_{2} \mathrm{O}\right)$ and dinitrogen $\left(\mathrm{N}_{2}\right)$ gases. The final product and the intermediates are released into the atmosphere so that fixed nitrogen is transformed into less bioavailable forms of nitrogen (Knowles 1982).

Denitrifying bacteria are a diverse group of microorganisms defined by their common respiratory physiology. They are facultative anaerobes that can switch from oxygen to nitrogen oxides as terminal electron acceptors (Knowles 1982, Philippot 2002). Two structurally different nitrite reductases that carry out the same reaction are found among denitrifiers. One, encoded by the nirK gene, contains copper (Cu-Nir), and the other, encoded by the nirS gene, contains cytochromes $c$ and $d_{1}\left(c d_{1}\right.$-Nir) (Zumft 1997). The gene nirS is part of a cluster containing several other genes involved in the production of the active enzyme (Zumft 1997, Philippot 2002). The gene nirK does not seem to belong to a gene cluster, with the only exception of nitrifying bacteria in which it has been observed as part of an operon (Beaumont et al. 2005). So far, only 1 of these 2 genes is found in any particular denitrifying strain, but different strains of the same species may contain different nir genes (Coyne et al. 1989).

Using the nitrite reductase genes as functional markers, the community composition of denitrifying bacteria has been studied in different habitats, including soil (Avrahami et al. 2002, Prieme et al. 2002, Rösch et al. 2002), groundwater (Yan et al. 2003), estuarine sedi- 
ment (Nogales et al. 2002), marine sediments (Braker et al. 2000, 2001), aquifers (Santoro et al. 2006), seawater (Jayakumar et al. 2004, Castro-Gonzalez et al. 2005 ) and the oxygen minimum zone of the Black Sea (Oakley et al. 2007). In marine environments a shift in the community structure of nirS denitrifying bacteria occurs along the physical-chemical gradient in the stratified water column (Castro-Gonzalez et al. 2005, Oakley et al. 2007). However, similar studies have never been carried out in stratified freshwater lakes.

Lake Kinneret is a monomictic subtropical freshwater lake located in the northern part of Israel. The water column shows a distinct seasonal pattern of chemical stratification characterized by changes in the concentration of dissolved oxygen, nitrate and sulfide. During the period of mixing (December to March), the concentrations of oxygen and nitrate are high throughout the water column. With the onset of thermal stratification in April, followed by the degradation and decomposition of the massive bloom of the dinoflagellate Peridinium gatunense in May, oxygen is consumed and gradually depleted in the hypolimnion so that anoxic conditions arise. At the onset of anaerobiosis, the activity of denitrifying bacteria in the anoxic hypolimnion leads to the use of nitrate. After depletion of the nitrate, sulfate reduction becomes the dominant microbial process in this layer (Hadas \& Pinkas 1995, Eckert et al. 2002).

During stratification, the distribution of denitrifying communities in the water column is unknown, but is probably coupled to nitrification in the chemocline. We applied molecular techniques combining PCR amplification, terminal restriction fragment length polymorphism (T-RFLP) and clone library analysis to examine the community composition of denitrifying bacteria at various depths of the stratified water column of Lake Kinneret.

\section{MATERIALS AND METHODS}

Site description. Lake Kinneret is situated in the northern part of Israel at $210 \mathrm{~m}$ below sea level. The lake is stratified from May to December. All water samples were collected on the same day at Stn A (maximum depth $42 \mathrm{~m}$ ) in October 2004, during the stable stratification period. The composition of the denitrifying bacterial communities was analyzed at 4 depths of the water column, defined by their chemical characteristics (Table 1): $1 \mathrm{~m}$ represented the oxygenated surface mixed layer of the epilimnion, $14 \mathrm{~m}$ the boundary between epi- and meta- limnion (lower dissolved oxygen concentrations and decline in temperature), and 19 and $22 \mathrm{~m}$ the lower metalimnion and hypolimnion (anoxic water), respectively.

DNA extraction and PCR amplification of nirS and nirK genes. Water samples $(400 \mathrm{ml})$ were filtered onto $0.2 \mu \mathrm{m}$ pore size filters (Supor-200, PALL Life Sciences), and stored at $-18^{\circ} \mathrm{C}$. DNA was extracted using the UltraClean Soil DNA kit (MoBio) following the manufacturer's guidelines. Concentration and quality of the DNA was checked by electrophoresis in $0.8 \%$ agarose gels stained with ethidium bromide. For nirS amplification the primers cd3aF (Michotey et al. 2000) and R3cd (Throbäck et al. 2004) were used. For nirK the primers F1aCu and 3Rcu (Hallin \& Lindgren 1999) were applied. These primer sets were selected according to the results of a recent re-evaluation of primers for amplifying genes involved in denitrification in which these combinations performed the best for cultured strains and environmental samples (Throbäck et al. 2004). PCR reactions were carried out as mentioned elsewhere (Hallin \& Lindgren 1999, Throbäck et al. 2004) except that the annealing temperature was increased to $57^{\circ} \mathrm{C}$. The expected size of the products was about 410 bp for nirS and $470 \mathrm{bp}$ for nirK.

T-RFLP. In total 8 samples were analyzed with TRFLP. PCR products that had been purified with multiscreen plates (Millipore) were diluted 1:100 in autoclaved HPLC water and used as template for reaction with the labeled primers R3Cd-HEX (nirS) and F1aCuFAM (nirK). To minimize the effect of PCR drift factors (Polz \& Cavanaugh 1998), each amplification was carried out in triplicate. The products were pooled, purified using the Qiaquick PCR Purification Kit (Qiagen) and quantified in the gel using Molecular Analysis software (BioRad). The labeled product (20 to $40 \mathrm{ng}$ ) was digested with the restriction enzymes HaeIII, AluI and MspI (New England Biolabs), respectively. Restrictions were carried out in $10 \mu \mathrm{l}$ with $10 \mathrm{U}$ of enzyme and $1 \times$ the indicated buffer. After overnight digestion at $37^{\circ} \mathrm{C}$ the reactions were incubated for $10 \mathrm{~min}$ at $95^{\circ} \mathrm{C}$ to inactivate the restriction enzymes. DNA was ethanol precipitated (BigDye 3.1v sequenc-

Table 1. Chemical characteristics at the sampling depths. NTU = nephelometer turbidity units, SpCond = electrical conductivity

\begin{tabular}{|lccccccc|}
\hline $\begin{array}{l}\text { Depth } \\
(\mathrm{m})\end{array}$ & $\begin{array}{c}\text { Temp } \\
\left({ }^{\circ} \mathrm{C}\right)\end{array}$ & $\begin{array}{c}\text { Dissolved oxygen } \\
(\% \text { saturation) }\end{array}$ & $\begin{array}{c}\text { SpCond } \\
\left(\mathrm{mg} \mathrm{l}^{-1}\right)\end{array}$ & $\begin{array}{c}\text { Turbidity } \\
\left(\mathrm{mS} \mathrm{cm}^{-1}\right)\end{array}$ & $\mathrm{pH}$ & $\begin{array}{c}\text { Redox } \\
(\mathrm{mV})\end{array}$ \\
\hline 1 & 28.0 & 92.2 & 7.4 & 1.0 & 1.5 & 8.8 & 150.0 \\
14 & 26.8 & 23.3 & 1.9 & 1.0 & 0.0 & 8.7 & -66.0 \\
19 & 26.1 & 1.6 & 0.1 & 1.1 & 4.2 & 7.7 & -62.0 \\
22 & 18.2 & 1.6 & 0.2 & 1.1 & 0.1 & 7.6 & -205.0 \\
\hline
\end{tabular}


ing kit manual, Applied Biosystems), and resuspended in $9 \mu \mathrm{l}$ of high-denaturing formamide mixture containing the size standard ROX-500 (Applied Biosystems). Restriction fragments were separated in an ABI 3100 automatic sequencer with the GeneScan36-POP4 default module.

Data analysis. Data were analyzed using GeneScan 3.1 software (Applied Biosystems). Values of peak height were normalized relative to the sample with the lowest fluorescence and the threshold of peak detection set to 50 relative fluorescence units (FU) of the normalized data. After normalization, a table with the relative peak height of each terminal restriction fragment (T-RF) was constructed. Statistical analyses were carried out with Primer 6 software (Primer E) and Statistica 6 (Statsoft), as described elsewhere (Wolsing \& Prieme 2004). In the principal component analysis (PCA) the samples were classified based on the presence or absence of T-RFs. Additionally, the environmental variables shown in Table 1 were included as secondary variables in the PCA. These secondary variables were also classified based on the 2 principal components calculated with the presence/absence matrix of T-RFs. Simulation of T-RF profiles of the clones was carried out with the program TRiFLe (P. Junier et al. unpubl.). This program simulates PCR and restriction reactions with those sequences that can be detected with the selected primers, producing a list of T-RFs that can be compared with the experimental T-RFs obtained from the environmental samples.

Cloning. In order to minimize PCR errors, the proofreading Pfu DNA polymerase (Promega) was used to produce the PCR products for cloning with the Zero Blunt PCR Cloning Kit (Invitrogen) according to the manufacturer's guidelines. Products from 3 independent PCRs were combined, concentrated on a Multiscreen plate (Millipore), and agarose gel-purified using the Gel Extraction Kit (Qiagen). Forty-eight clones were picked randomly from each cloning and checked for inserts of the expected size by PCR with the plasmid-specific primers M13f/M13r, and agarose electrophoresis. For screening of these clones, oneshot sequencing with M13f primer was performed using the BigDye terminator v3.1 cycle sequencing kit. Sequences were analyzed with an ABI 3100 Genetic Analyzer (Applied Biosystems) according to the manufacturer's recommendations. The resulting nucleotide sequences were compared with sequences in the GenBank database by using translated BLASTX (Altschul et al. 1997) on the NCBI homepage (http:// blast.ncbi.nlm.nih.gov/Blast.cgi). Clones were grouped according to the BLAST results. From each group 1 clone was selected for sequencing of both strands. These sequences have been deposited in GenBank under the accession numbers EF623493 to EF623527.
Phylogenetic analyses. Phylogenetic analyses were carried out with the software ARB (www.arbhome.de). Databases of nirS and nirK were created using all sequences available in GenBank. Phylogenetic trees of protein-coding genes were constructed from amino acid sequences with the PHYLIP subroutine in $A R B$, in which a neighbor-joining algorithm used results of a substitution matrix calculated with the Jones-Taylor-Thornton (JTT) model.

Nitrogen species $\left(\mathrm{NH}_{4}{ }^{+}, \mathrm{NO}_{2}^{-}, \mathrm{NO}_{3}^{-}\right)$concentration measurements. Lake water samples were filtered through a $0.45 \mu \mathrm{m}$ filter $(\mathrm{S} \& \mathrm{~S})$, and then $\mathrm{NH}_{4}{ }^{+}, \mathrm{NO}_{2}{ }^{-}$ and $\mathrm{NO}_{3}^{-}$concentrations were measured spectrophotometrically by Standard Methods or with a Flow Injection System (QuikChem 8000 Automated Ion Analyzer, Lachat Instruments).

\section{RESULTS}

\section{T-RFLP analysis of nirS and nirK}

Nitrate concentrations were about $25 \mu \mathrm{g} \mathrm{l^{-1 }}$ in the epilimnion (1 and $14 \mathrm{~m}$ ) and undetectable below $18 \mathrm{~m}$. Ammonium concentrations were low in the epilimnion $\left(\sim 25 \mu \mathrm{g} \mathrm{l}^{-1}\right)$ and increased in the thermocline/chemocline, reaching values of $500 \mu \mathrm{g} \mathrm{l}^{-1}$ at $22 \mathrm{~m}$.

The enzymes that produced the highest number of $\mathrm{T}$ RFs in the water samples were AluI (13 T-RFs) for nirs and HaeIII (20 T-RFs) for nirK (Figs. 1 \& 2).

Differences in the community structure between the samples were analyzed based on the relative fluorescence of each T-RF in the T-RFLP pattern. In the community of denitrifying bacteria with nirS, a single T-RF (221 bp; Fig. 1) was found most frequently at all depths. Three additional T-RFs (49, 232 and 405 bp) were also common to all samples. These 4 T-RFs represented between 79 and $99 \%$ of the total fluorescence in the samples. The community of denitrifiers containing nirs at $1 \mathrm{~m}$ was the most diverse and contained several unique T-RFs $(76,131,204,221,274$ and $374 \mathrm{bp}$ ).

The community structure of denitrifying bacteria carrying nirK changed more substantially with depth than those containing nirS (Fig. 2). Although the nirK T-RFs 173 and $231 \mathrm{bp}$ were common to all samples, each depth was dominated by a different T-RF. At $1 \mathrm{~m}$ depth, the dominant fragment was the T-RF 264 bp, which also appeared at 14 and $19 \mathrm{~m}$, but not at $22 \mathrm{~m}$. The T-RF 59 bp was observed at depths of 14, 19 and $22 \mathrm{~m}$, but not at $1 \mathrm{~m}$. At $22 \mathrm{~m}$ it represented the major proportion of fluorescence. The community of denitrifiers containing nirK was more diverse at $22 \mathrm{~m}$ depth and showed several distinctive T-RFs $(97,100,111,159$ and $162 \mathrm{bp}$ ). 


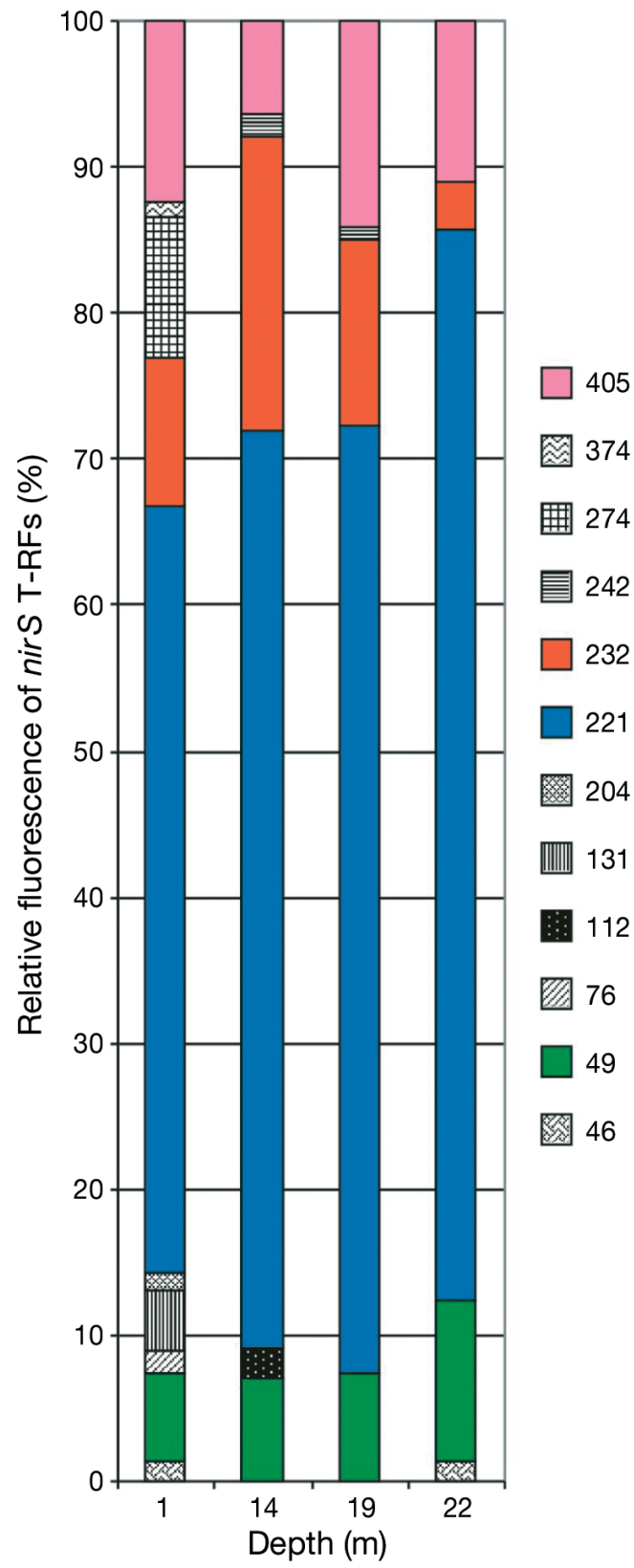

Fig. 1. T-RFLP analysis of nirS PCR products digested with AluI. T-RF sizes (bp) are shown on the right. T-RFs that were assigned to clones in the libraries are shown in color

\section{Statistical analysis of T-RFLP}

To determine the underlying community structure, results from restrictions with HaeIII, AluI and MspI were combined and analyzed by multivariate statistical analysis. Three ordination methods were used: PCA, multidimensional scaling (MDS) and cluster analyses of T-RFLP profiles. The results from the different methods were consistent and therefore only results from PCA are shown (Fig. 3).

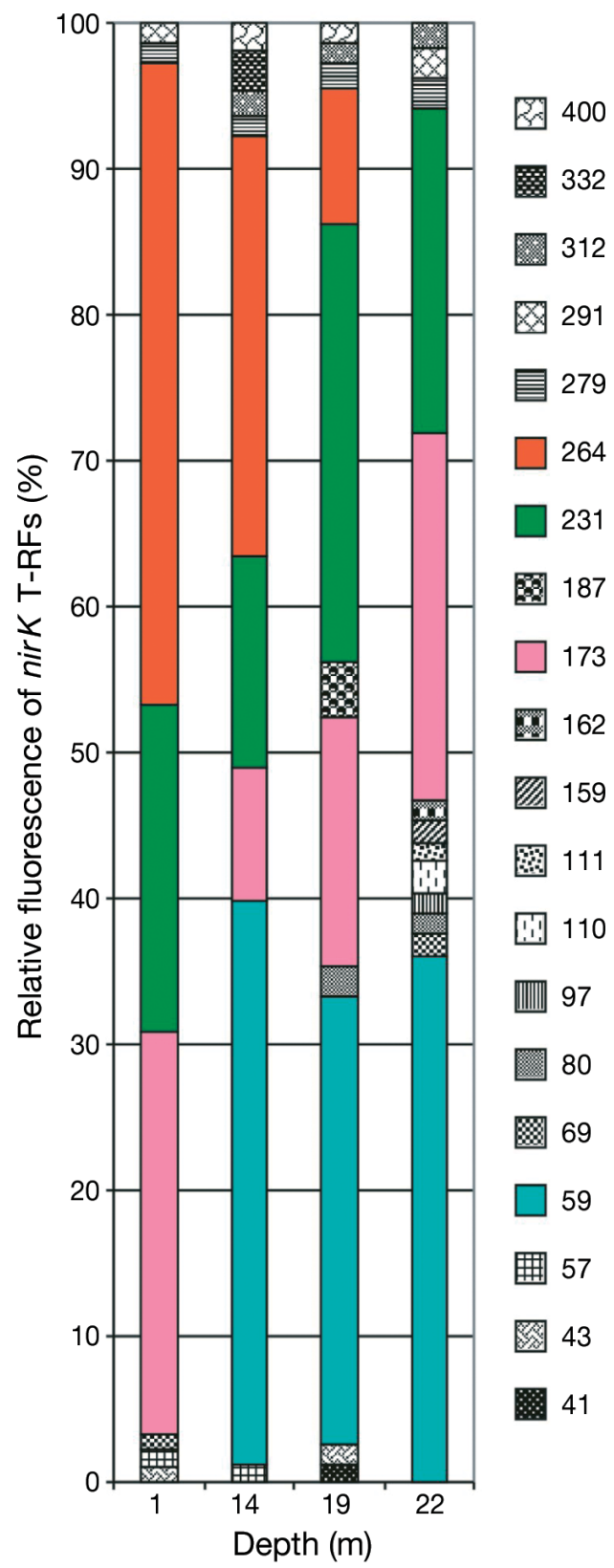

Fig. 2. T-RFLP analysis of nirK PCR products digested with HaeIII. T-RF sizes (bp) are shown on the right. T-RFs that were assigned to clones in the libraries are shown in color

In the PCA of the T-RFLP of nirS, the first principal component (PC1), which accounted for $56 \%$ of the variance, separates the $1 \mathrm{~m}$ sample from the other depths (Fig. 3A). This separation is explained by the presence of several unique T-RFs that appeared only at the $1 \mathrm{~m}$ depth and distinguished this community from the others, e.g. the T-RFs 76, 131, 204, 221, 274 and $374 \mathrm{bp}$ from the digestion with AluI (Fig. 1). The separation of the nirS denitrifying communities at 19 and $22 \mathrm{~m}$ from those at 1 and $14 \mathrm{~m}$ coincides with differ- 

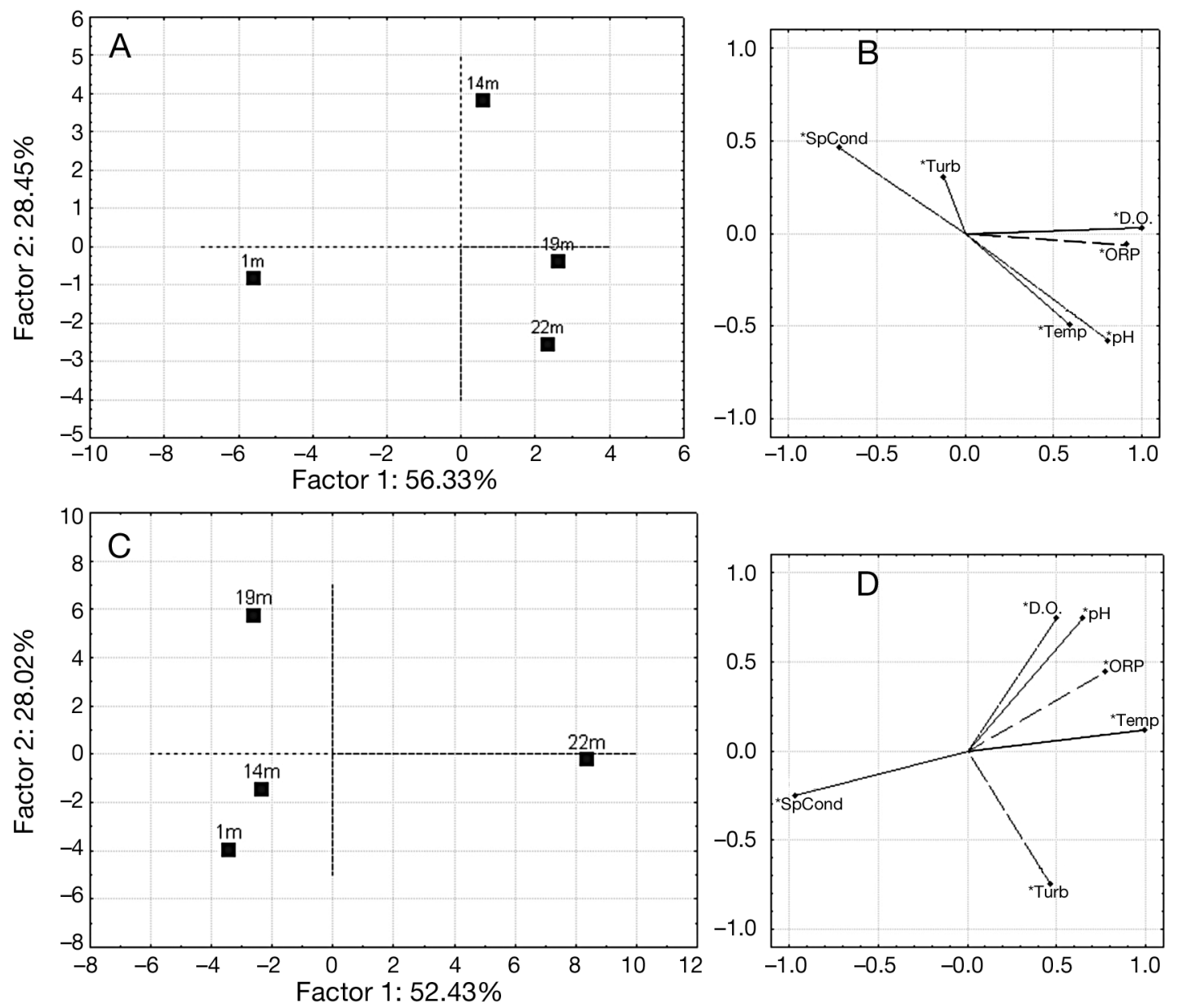

Fig. 3. Principal component analysis (PCA) of T-RFLP patterns of nirS and nirK. (A) PCA of nirS. (B) Separation of environmental variables analyzed as secondary variables in the PCA of nirS. (C) PCA of nirK. (D) Separation of environmental variables analyzed as secondary variables in the PCA of nirK. D.O.: dissolved oxygen; ORP: Redox potential; SpCond: electrical conductivity; Temp.: temperature; Turb.: turbidity

ences in dissolved oxygen, $\mathrm{pH}$, redox and temperature, which are all associated with water stratification (Table 1, Fig. 3B).

For nirK, the PC1 $(52 \%$ of the variance) distinguishes the nirK denitrifiers at $22 \mathrm{~m}$ from those in the other depths (Fig. 3C). This separation is also due to the presence of various unique T-RFs at $22 \mathrm{~m}$. In the case of nirK, temperature was associated with the separation of the sample from the hypolimnion (Fig. 3D).

\section{Cloning and sequence analysis of nirS and nirK}

The samples from 1 and $22 \mathrm{~m}$ were chosen for cloning and sequencing because they were differentiated among depths or between genes. Samples from $19 \mathrm{~m}$ were also examined because they originated from the boundary between the oxygenated surface water and the anoxic hypolimnion. Initial screening of the nirS and nirK clone libraries by one-shot sequencing with the primer M13f and BLAST search showed that the 85 nirs sequences could be separated into 9 groups, while the 120 nirK clones were separated into 5 groups (Table 2). Matched identity of the inferred protein sequences of these groups with the most similar nitrite reductases in GenBank ranged from 75 to $99 \%$ (Table 2), and corresponded in almost all cases (except 1) to uncultured denitrifying bacteria. The only exception was the group IIa of nirK that showed 99\% matched identity with NirK from Ochrobactrum sp. 3CB4.

The library of the PCR products from $1 \mathrm{~m}$ prepared with the primers for nirK contained more than $90 \%$ of clones that did not significantly match with sequences in the GenBank. Similar sequences were also detected at $19 \mathrm{~m}$, but not at $22 \mathrm{~m}$. To characterize these products, specific BLAST tools (tBLAST and PHI- 


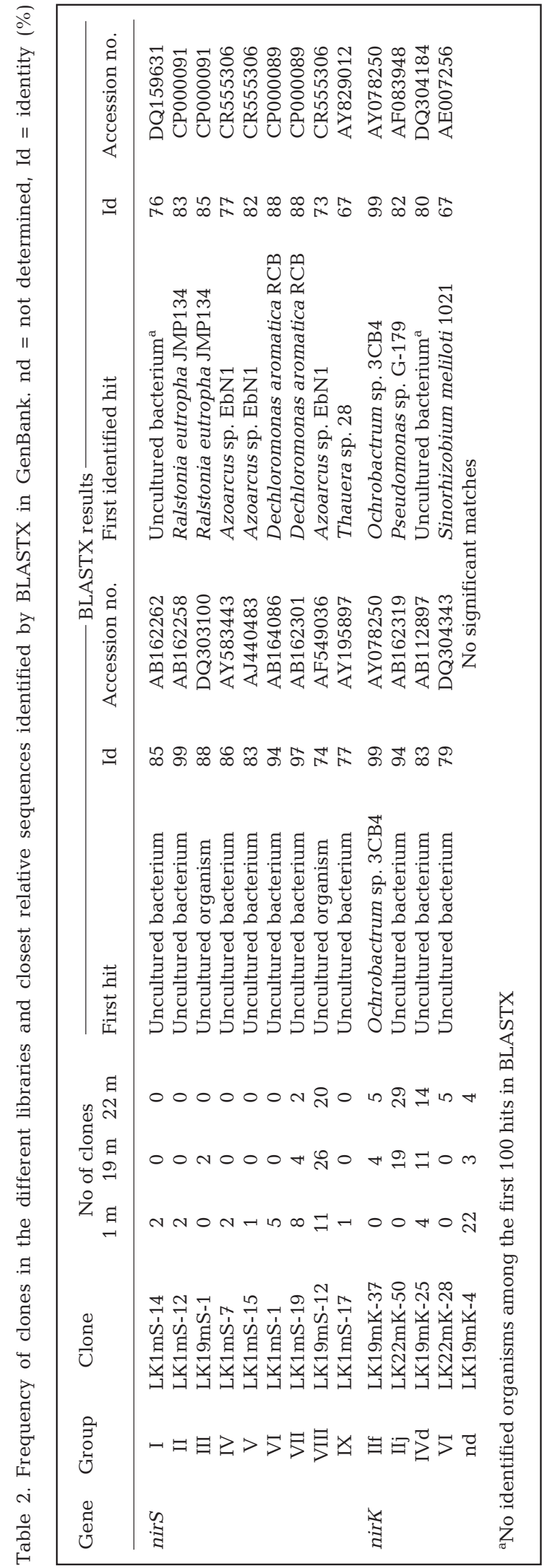

BLAST) were used. After this analysis, the deduced protein sequence from the clones was only $40 \%$ similar to the histidyl-tRNA synthetase from Rhodopirellula baltica.

In the phylogenetic analysis, the nirS sequences from Lake Kinneret were assigned to 9 groups (Fig. 4), having as closest relatives sequences from soil or activated sludge, rather than those from other aquatic environments. Group VIII, which contained the majority of the clones from all depths (Table 2), was distantly related to a clonal sequence from nitrate- and uranium-contaminated groundwater (Yan et al. 2003). The clusters VI and VII, which were also frequent especially in the library from $1 \mathrm{~m}$ depth, were related to sequences from nitrate- and uranium-contaminated groundwater and Dechloromonas spp. With the exception of group III, which was specific for the library from $19 \mathrm{~m}$, all the other clusters were detected at $1 \mathrm{~m}$ depth only (Table 2 ).

In the phylogenetic analysis of nirK, the clones were assigned to 4 groups (Fig. 5). The subgroup IIj dominated the libraries from 19 and $22 \mathrm{~m}$ depth, and had as closest relatives nirK sequences from uncultured soil bacteria. This subgroup, as well as IIf, belonged to a cluster related to sequences from different species of Ochrobactrum and other cultured denitrifiers. The group IVd, which was found in both libraries (Table 2), was related to nirK from soil and Azospirillum spp. Group IVd formed a subcluster inside cluster IV defined by Prieme et al. (2002). Sequences from group VI were observed only in the library from $22 \mathrm{~m}$, and were distantly related to clonal sequences from soil contaminated with silver.

Sequences that did not have a significant match in GenBank (Table 2) were also included in the phylogenetic analysis. These sequences formed the cluster 'nd' (not determined), which is unrelated to the other clonal sequences from Lake Kinneret.

\section{Assignment of nirS and nirK clones to T-RFs}

To correlate the T-RFs observed in the samples with the sequences in the clone libraries, the T-RFLP data were simulated with the nirS and nirK clonal sequences (Table 3).

Studies with other genes have shown that differences between theoretical and experimental T-RFs,

Fig. 4 (next 2 pages). Phylogeny of partial nirS sequences. Accession numbers of reference sequences are given. Sequences from this study are shown in bold. The number of identical sequences is indicated in parentheses. Bootstrap values $>85 \%$ are indicated. Numbers inside the boxes represent the number of sequences included in the group 


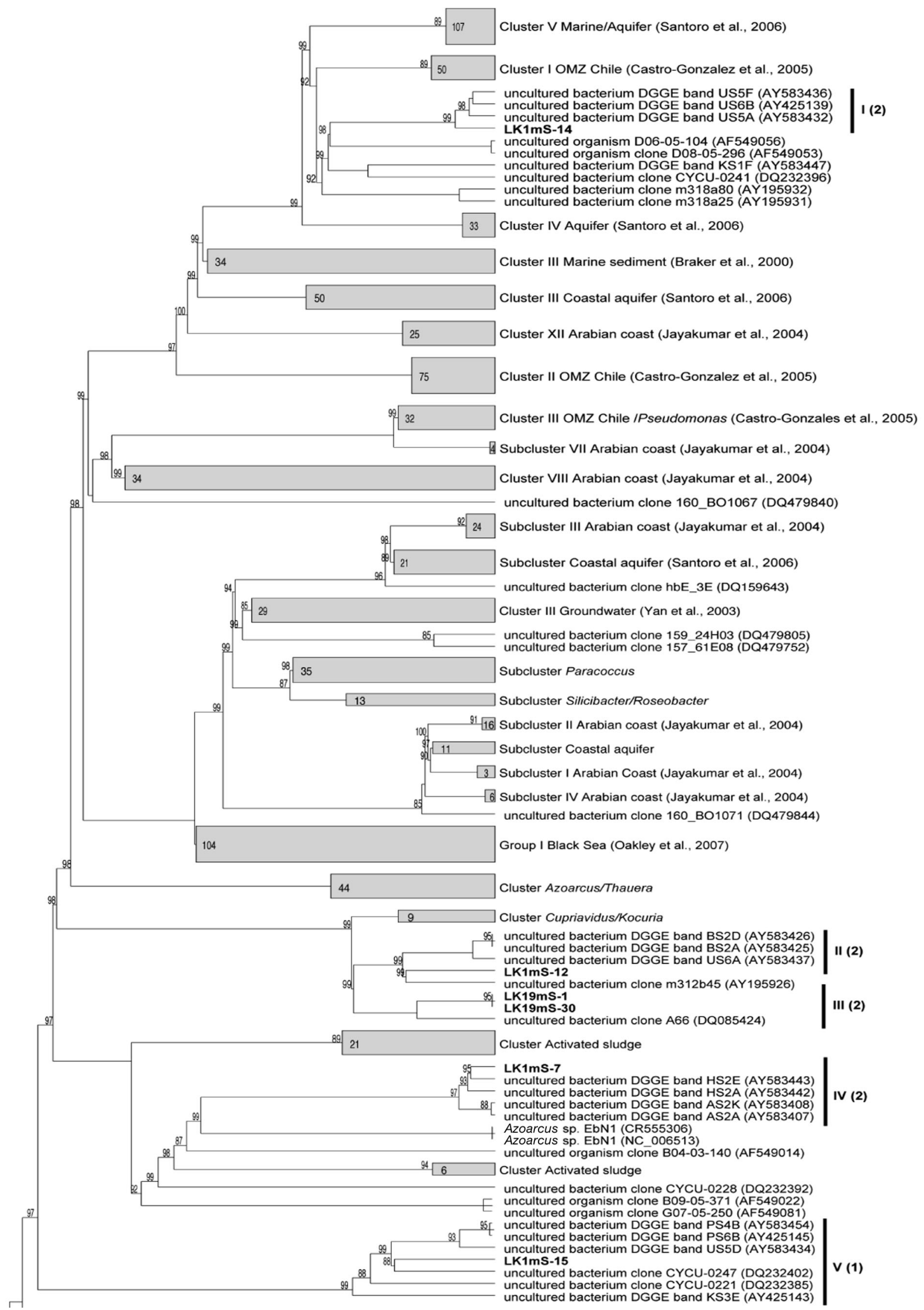

Fig. 4 (continued on next page) 


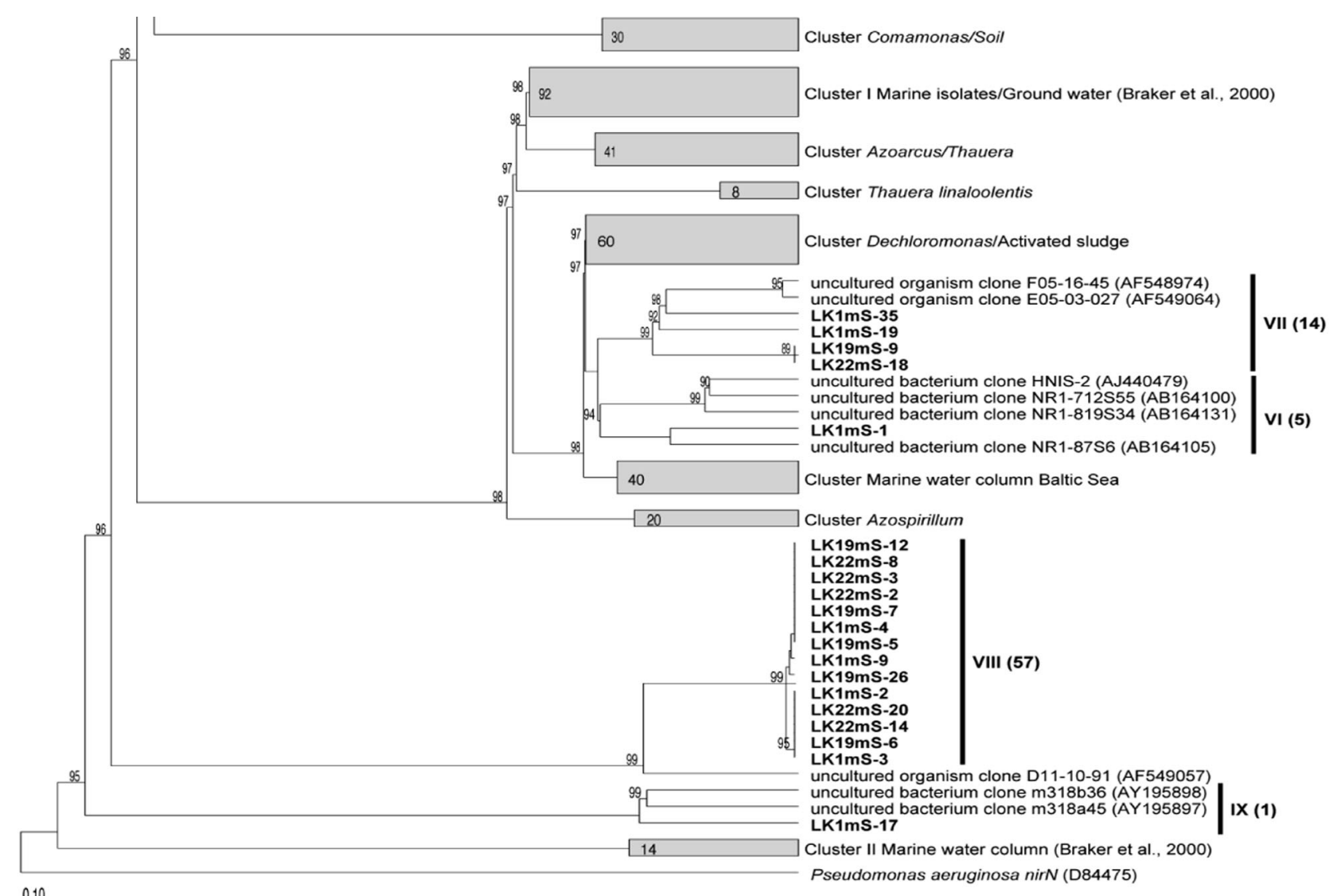

Fig. 4 (continued)

also called T-RF drift (Kitts 2001, Kaplan \& Kitts 2003, Lueders \& Friedrich 2003), do exist. In most of our experiments, this drift was $\leq 1 \%$ of the size of the T-RF (data not shown). Therefore a tolerance limit of $1 \%$ of the size of the fragment was chosen for comparison between simulated and experimental T-RFs, meaning that an experimental T-RF of $100 \mathrm{bp}$ was assigned to a theoretical T-RF of 99 to $101 \mathrm{bp}$ (1 bp of tolerance).

Despite the fact that AluI produced the highest number of fragments in the T-RFLP analysis of the nirS samples, AluI had a very low resolution for discriminating groups of clones in the libraries (Table 3). Considering the T-RF drift, the dominant T-RF observed in the samples (T-RF 221 bp, Fig. 1) can be assigned to several groups (I, II, III, V and VIII with a T-RF 224 bp). Other T-RFs that could be assigned were 49 bp (group IV), 232 bp (groups VII and VI) and 405 bp (group IX).

The assignment of the simulated T-RF was clearer for nirK than for nirS. Based on the results of the most polymorphic enzyme (HaeIII), the T-RF $59 \mathrm{bp}$ can be assigned to group IIj, the T-RF 173 bp to group IVd, and the T-RF 231 bp to group IIf. The T-RF 264 bp, which dominates in the profiles and the clone library from $1 \mathrm{~m}$, can be linked to the group of non-nirK sequences.

\section{DISCUSSION}

In the present study, denitrifying bacterial communities were analyzed in water samples from 4 depths of the stratified water column of Lake Kinneret. While nirS and nirK sequences from freshwater environments are scarce in the public databases, both types of nitrite reductase genes were detected in all depths. The simultaneous amplification of nirS and nirK has been difficult in environments such as soil and sediments (Braker et al. 2000, Avrahami et al. 2002, Prieme et al. 2002, Wolsing \& Prieme 2004). In water samples, however, this seem to be possible (Oakley et al. 2007).

The simultaneous detection of both genes in the present study is an opportunity to compare the structure of denitrifying bacterial communities carrying nirS or nirK and their habitat preferences in this stratified system. Virtually nothing is known about the environmental preferences of denitrifying bacteria (Prieme et al. 2002). According to our results from T-RFLP and clone libraries, the diversity of denitrifying communities carrying nirS or nirK varies at different depths of the water column of Lake Kinneret. Oxygen, nitrate (Liu et al. 2003, CastroGonzalez et al. 2005), dissolved organic carbon, inor- 


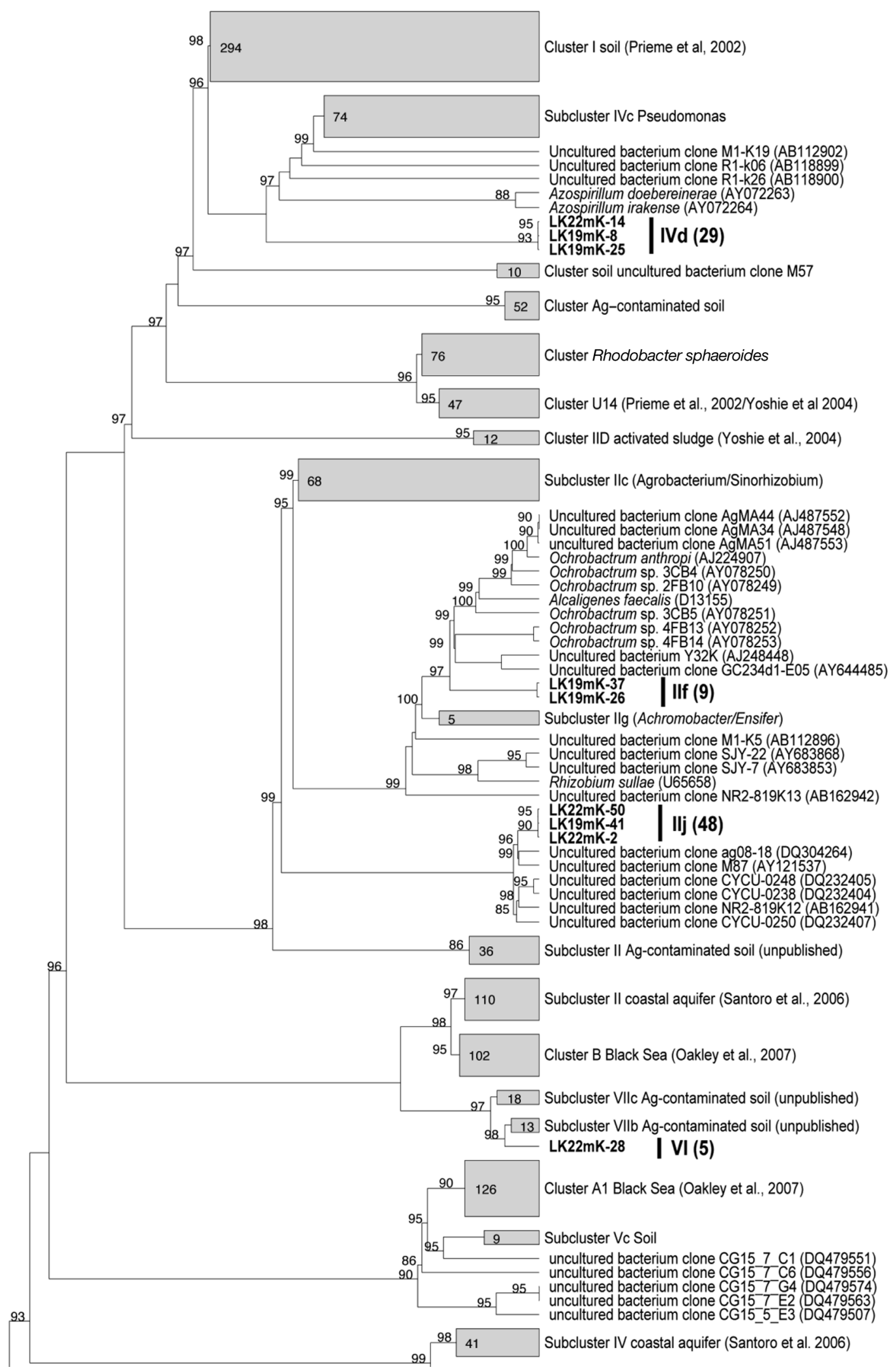

Fig. 5 (this page and next page). Phylogeny of partial nirK sequences. For explanation see Fig. 4 legend 


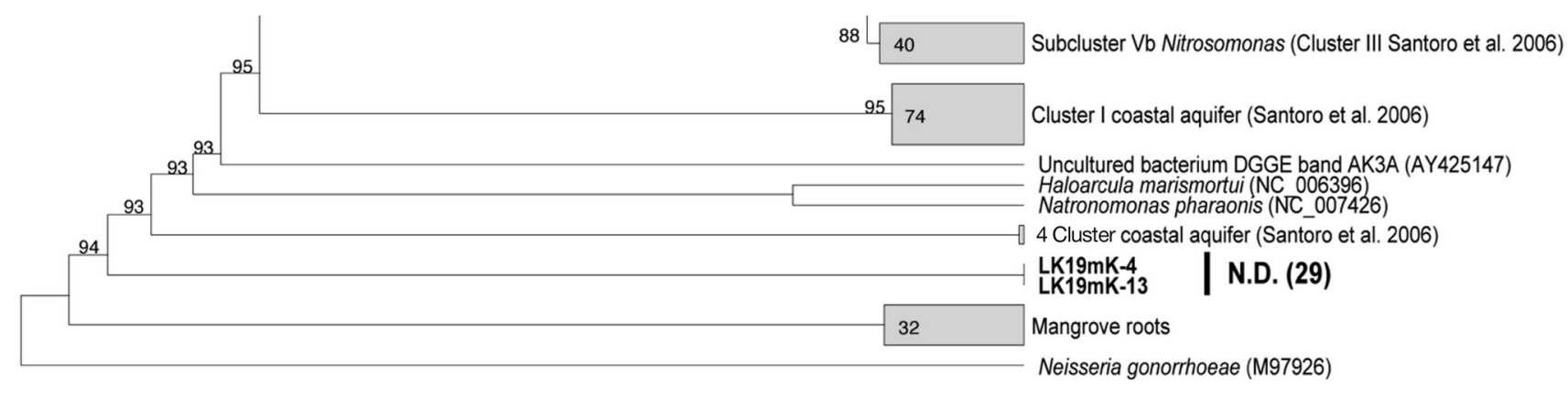

0.10

Fig. 5 (continued)

Table 3. Theoretical terminal restriction fragments (T-RFs) calculated for each group of clones from Table 2 . nd $=$ not determined

\begin{tabular}{|cclrrr|}
\hline \multirow{2}{*}{ Gene } & \multirow{2}{*}{ Group } & \multirow{2}{*}{ Clone } & \multicolumn{3}{c|}{ Theoretical T-RFs } \\
& & & MspI & AluI & Hae III \\
\hline \multirow{6}{*}{ nirS } & I & LK1mS-14 & 89 & 224 & 42 \\
& II & LK1mS-12 & 146 & 224 & 43 \\
& III & LK19mS-1 & 133 & 224 & 70 \\
& IV & LK1mS-7 & 130 & 50 & 42 \\
& V & LK1mS-15 & 133 & 224 & 70 \\
& VI & LK1mS-1 & 32 & 236 & 144 \\
& VII & LK1mS-19 & 31 & 236 & 151 \\
& VIII & LK19mS-12 & 89 & 224 & 88 \\
& IX & LK1mS-17 & 38 & 410 & 70 \\
nirK & IIf & LK19mK-37 & 137 & 473 & 235 \\
& IIj & LK22mK-50 & 137 & 473 & 64 \\
& IVd & LK19mK-25 & 136 & 473 & 176 \\
& VI & LK22mK-28 & 297 & 473 & 23 \\
& nd & LK19mK-4 & 82 & 24 & 269 \\
\hline
\end{tabular}

ganic nitrogen and salinity gradients (Taroncher-Oldenburg et al. 2003) have been identified as influencing the composition of denitrifying bacterial communities along physical-chemical gradients. In our study, differentiation of the communities in the meta- and hypolimnion (19 and $22 \mathrm{~m}$ in depth) was related to dissolved oxygen concentration, $\mathrm{pH}$, and temperature, parameters that are directly linked to stratification. However, the differentiation of the communities in the epilimnion, in which a higher diversity of denitrifiers carrying nirS was found, was not directly related to any of the environmental variables measured (Table 1).

It is well established that trace metals, particularly iron (NirS) and copper (NirK) (Zumft 1997), are necessary for the activity of nitrite reductases. In Lake Kinneret most of the bioavailable iron occurs in particles that are restricted to the epilimnion during stratification (Shaked et al. 2004). It can be hypothesized that differences in bioavailability of iron and other trace metals might favor denitrifying bacterial communities with nirS in the epilimnion of the lake.
Considering the physiological diversity of the denitrifying bacteria, it is possible that the factors affecting the distribution of the different groups observed at specific depths are not at all correlated with their denitrifying capabilities. Other variables such as the source of carbon or the general tolerance to oxygen may better explain the diversity of denitrifying bacteria carrying nirS in the epilimnion, but this needs to be verified in further studies. The bacterial distribution may be influenced by the nature of the microniches with low oxygen concentrations, which may exist in larger aggregates or detritus particles, in the otherwise oxic epilimnion.

According to the T-RFLP analysis and clone libraries, denitrifying bacterial communities carrying nirS were dominated by organisms that were common in all the depths, but that seem to be able to exploit different environmental niches. In contrast, only one cluster of nirK sequences was common to all the depths; this cluster did not correspond to the dominant group. In Lake Kinneret, bacteria carrying nirK appear to be adapted to the specific environmental conditions in each layer of the stratified water column. A similar tendency was observed in a salinity gradient in a beach aquifer at Huntington Beach (California) where different clades of nirK sequences were associated to specific salinities, whereas nirS did not show any specific environmental adaptation (Santoro et al. 2006). Also, a recent study in the suboxic zone of the Black Sea (Oakley et al. 2007) showed much greater variation of nirK sequences at the bottom of the suboxic zone, while nirS sequences were more homogeneously distributed.

The nirS and nirK sequences from Lake Kinneret differed from those of marine habitats and coastal aquifers (Jayakumar et al. 2004, Castro-Gonzalez et al. 2005, Francis et al. 2005, Santoro et al. 2006). This suggests a differentiation of marine and purely freshwater denitrifying bacteria carrying nirS, but has to be substantiated by additional studies. Group VIII, which contained most of the clones of this study and dominated in the libraries from all depths, seems to be a 
hitherto undescribed group of denitrifiers specific for Lake Kinneret.

The topology of the nirK phylogeny obtained in our study resembled those from previous studies (Casciotti \& Ward 2001, Avrahami et al. 2002, Prieme et al. 2002). Sequences from Lake Kinneret formed 3 new subclusters inside the clusters II and IV defined by Prieme et al. (2002). The new cluster VI appears to be specific for Lake Kinneret. The closest relatives of most nirK clonal sequences from Lake Kinneret were uncultured clones from agricultural soil (Avrahami et al. 2002) or marsh soil (Prieme et al. 2002). Although this situation might suggest a terrestrial origin of the denitrifying bacteria carrying nirK in the lake, it might also be due to the low number of nirK sequences from aquatic environments that are available for comparison.

Targeting the nirK and nirS genes would detect denitrifiers irrespective of their activity (Braker et al. 1998). Thus, the data obtained in the present study represent a genetic characterization that constitutes a framework for a more detailed study of the function and activity of denitrifying communities in Lake Kinneret. It also constitutes one of the first analyses of this kind in the water column of freshwater lakes, where community composition and diversity of denitrifying bacteria have previously been unknown.

Acknowledgements. This research was supported by German-Israel Foundation (GIF) grant no. I-711-83.8/2001 and Binational Science Foundation (BSF) grant no. 2002-206. Samples were taken during the German Israeli Minerva School in October 2004. We thank the Yigal Allon Kinneret Limnological Laboratory personnel for their assistance during the sampling. We thank the Max Planck Society and the GIF for financial support of P. Junier and O. S. Kim during this study.

\section{LITERATURE CITED}

Altschul SF, Madden TL, Schäffer AA, Zhang J, Zhang Z, Miller W, Lipman DJ (1997) Gapped BLAST and PSIBLAST: a new generation of protein database search programs. Nucleic Acids Res 25:3389-3402

Avrahami S, Conrad R, Braker G (2002) Effect of soil ammonium concentration on $\mathrm{N}_{2} \mathrm{O}$ release and on the community structure of ammonia oxidizers and denitrifiers. Appl Environ Microbiol 68:5685-5692

> Beaumont HJ, Lens SI, Westerhoff HV, van Spanning RJ (2005) Novel nirK cluster genes in Nitrosomonas europaea are required for NirK-dependent tolerance to nitrite. J Bacteriol 187:6849-6851

> Braker G, Fesefeldt A, Witzel KP (1998) Development of PCR primer systems for amplification of nitrite reductase genes (nirK and nirS) to detect denitrifying bacteria in environmental samples. Appl Environ Microbiol 64:3769-3775

Braker G, Zhou J, Wu L, Devol AH, Tiedje JM (2000) Nitrite reductase genes (nirK and nirS) as functional markers to investigate diversity of denitrifying bacteria in Pacific Northwest marine sediment communities. Appl Environ Microbiol 66:2096-2104
Braker G, Ayala del Rio HL, Devol AH, Fesefeldt A, Tiedje JM (2001) Community structure of denitrifiers, bacteria, and archaea along redox gradients in Pacific Northwest marine sediments by terminal restriction fragment length polymorphism analysis of amplified nitrite reductase (nirS) and 16S rRNA genes. Appl Environ Microbiol 67: 1893-1901

Casciotti KL, Ward BB (2001) Dissimilatory nitrite reductase genes from autotrophic ammonia-oxidizing bacteria. Appl Environ Microbiol 67:2213-2221

Castro-Gonzalez M, Braker G, Farias L, Ulloa O (2005) Communities of nirS-type denitrifiers in the water column of the oxygen minimum zone in the eastern South Pacific. Environ Microbiol 7:1298-1306

Coyne MS, Arunakumari A, Averill A, Tiedje JM (1989) Immunological identification and distribution of dissimilatory heme $c d_{1}$ and non-heme copper nitrite reductases in denitrifying bacteria. Appl Environ Microbiol 55: 2924-2931

Eckert W, Imberger J, Saggio A (2002) Biogeochemical response to physical forcing in the water column of a warm monomictic lake. Biogeochemistry 61:291-307

Francis CA, Roberts KJ, Beman JM, Santoro AE, Oakley BB (2005) Ubiquity and diversity of ammonia-oxidizing archaea in water columns and sediments of the ocean. Proc Natl Acad Sci USA 102:14683-14688

Hadas O, Pinkas R (1995) Sulphate reduction in the hypolimnion and sediments of Lake Kinneret, Israel. Freshw Biol 33:63-72

Hallin S, Lindgren PE (1999) PCR detection of genes encoding nitrite reductase in denitrifying bacteria. Appl Environ Microbiol 6:1652-1657

> Jayakumar DA, Francis CA, Naqvi SWA, Ward BB (2004) Diversity of nitrite reductase genes (nirS) in the denitrifying water column of the coastal Arabian Sea. Aquat Microb Ecol 34:69-78

Kaplan CW, Kitts CL (2003) Variation between observed and true terminal restriction fragment length is dependent on true TRF length and purine content. J Microbiol Methods 54:121-125

Kitts CL (2001) Terminal restriction fragment patterns: a tool for comparing microbial communities and assessing community dynamics. Curr Issues Intest Microbiol 2:17-25

> Knowles R (1982) Denitrification. Microbiol Rev 46:43-70

- Liu X, Tiquia SM, Holguin G, Wu L and others (2003) Molecular diversity of denitrifying genes in continental margin sediments within the oxygen-deficient zone off the Pacific coast of Mexico. Appl Environ Microbiol 69:3549-3560

> Lueders T, Friedrich MW (2003) Evaluation of PCR amplification bias by terminal restriction fragment length polymorphism analysis of small-subunit rRNA and mcrA genes by using defined template mixtures of methanogenic pure cultures and soil DNA extracts. Appl Environ Microbiol 69:320-326

> Michotey V, Mejean V, Bonin P (2000) Comparison of methods for quantification of cytochrome $\mathrm{Cd}_{1}$-denitrifying bacteria in environmental marine samples. Appl Environ Microbiol 66:1564-1571

Nogales B, Timmis KN, Nedwell DB, Osborn AM (2002) Detection and diversity of expressed denitrification genes in estuarine sediments after reverse transcription-PCR amplification from mRNA. Appl Environ Microbiol 68: $5017-5025$

Oakley BB, Francis CA, Roberts KJ, Fuchsman CA, Srinivasan S, Staley JT (2007) Analysis of nitrite reductase (nirK and nirS) genes and cultivation reveal depauperate community of denitrifying bacteria in the Black Sea suboxic zone. Environ Microbiol 9:118-130 
Philippot L (2002) Denitrifying genes in bacterial and Archaeal genomes. Biochim Biophys Acta 1577:355-376

Polz MF, Cavanaugh CM (1998) Bias in template-to-product ratios in multitemplate PCR. Appl Environ Microbiol 64: 3724-3730

Prieme A, Braker G, Tiedje JM (2002) Diversity of nitrite reductase (nirK and nirS) gene fragments in forested upland and wetland soils. Appl Environ Microbiol 68: 1893-1900

Rösch C, Mergel A, Bothe H (2002) Biodiversity of denitrifying and dinitrogen-fixing bacteria in an acid forest soil. Appl Environ Microbiol 68:3818-3829

Santoro AE, Boehm AB, Francis CA (2006) Denitrifier community composition along a nitrate and salinity gradient in a coastal aquifer. Appl Environ Microbiol 72: 2102-2109

Shaked Y, Erel Y, Sukenik A (2004) The biogeochemical cycle of iron and associated elements in Lake Kinneret. Geochim Cosmochim Acta 68:1439-1451

Editorial responsibility: Samantha Joye, Athens, Georgia, USA
Taroncher-Oldenburg G, Griner EM, Francis CA, Ward BB (2003) Oligonucleotide microarray for the study of functional gene diversity in the nitrogen cycle in the environment. Appl Environ Microbiol 69:1159-1171

Throbäck IN, Enwall K, Jarvis A, Hallin S (2004) Reassessing PCR primers targeting nirS, nirK and nos $Z$ genes for community surveys of denitrifying bacteria with DGGE. FEMS Microbiol Ecol 49:401-417

> Wolsing M, Prieme A (2004) Observation of high seasonal variation in community structure of denitrifying bacteria in arable soil receiving artificial fertilizer and cattle manure by determining T-RFLP of nir gene fragments. FEMS Microbiol Ecol 48:261-271

Yan T, Fields MW, Wu L, Zu Y, Tiedje JM, Zhou J (2003) Molecular diversity and characterization of nitrite reductase gene fragments (nirK and nirS) from nitrate- and uraniumcontaminated groundwater. Environ Microbiol 5:13-24

Zumft WG (1997) Cell biology and molecular basis of denitrification. Microbiol Mol Biol Rev 61:533-616

Submitted: May 8, 2007; Accepted: February 12, 2008 Proofs received from author(s): April 28, 2008 